\title{
Student Views on the Value of Feedback
}

\author{
Jenny A. Marie \\ Correspondence: Jenny A. Marie, CALT, UCL, 1-19 Torrington Place, London, WC1E 7HB, UK.
}

Received: April 6, $2016 \quad$ Accepted: April 13, $2016 \quad$ Online Published: April 26, 2016

doi:10.11114/jets.v4i6.1523

URL: http://dx.doi.org/10.11114/jets.v4i6.1523

\begin{abstract}
This paper investigates the value that a sample of students placed on feedback, what they valued it for and the conditions that affected this value judgement. I show that not all students value feedback particularly highly, especially when considered in relation to other factors in their education and when considered for its intrinsic value as opposed to how it represents their value to their lecturers and the institution. I show that the students studied valued feedback most where they could see the possibilities for using it to improve future work: through a clear linkage between coursework and exams, the coursework being of sufficient weighting and the students appreciating that it can be used to improve. I argue that the students studied would have benefitted from more education about the value of feedback and how to use it productively. Further research is required to see how generalisable these findings are.
\end{abstract}

Keywords: feedback, value, learning, motivation, pastoral care

\section{Introduction}

The literature places high value on feedback. Research shows that feedback has the power to greatly enhance student learning (Hattie \& Timperley, 2007; Black \& Dylan, 1998). Feedback can help students to understand what a good piece of work looks like and how their work compares to this standard. It can help to direct independent learning, by showing where there are gaps in students' knowledge and understanding and feedback can provide instructional advice on how to improve.

This does not mean that students value feedback in the same way. In the UK, student satisfaction with academic courses is measured at the end of undergraduate degrees via the National Student Survey (NSS). Currently students answer 23 questions. The first 21 contribute towards six different scales, one of which is assessment and feedback, the 22nd question asks about overall satisfaction and the 23rd asks about satisfaction with their Student Union. Research into correlations between these scales and overall satisfaction showed that the correlation between satisfaction with assessment and feedback and overall satisfaction was one of the lowest correlations between any of the scales and overall satisfaction (Buxley, 2012). In other words, how students feel about assessment and feedback does not have great bearing on how they feel about their degrees.

Across the sector, there are issues of students not collecting feedback (Gibbs \& Simpson, 2004; Sinclair and Cleland, 2007). This could be due to logistical issues - students in the focus groups reported on in this paper complained about having to collect feedback from a lecturer in another building and then commonly finding the lecturer out of their office, having to find their feedback amongst a large pile 'dumped' in the common room and some students were not informed that their feedback was ready for collection. Nevertheless, the high level of uncollected feedback suggests that students do not value feedback sufficiently to overcome such barriers.

This paper investigates the value that some students at a research-intensive university place on feedback - both what it is valued for, how much value they assign to it and the paper considers the conditions that relate to these value judgements. The paper suggests ways in which feedback's intrinsic value to these students could be increased. This should make them more likely to collect and make the best use of feedback. Further research is required to see how applicable this is to other students in different contexts.

\subsection{Relevant Scholarship}

There are a number of papers on student perceptions of feedback. These tend to report that students value feedback (Ferguson, 2011; Rae \& Cochrane, 2008), though as Weaver (2006) points out while students may value feedback there can be a gap between its potential and actual value.

Students differ in their views of the importance of feedback. Brown (2007) found that students' desire for feedback 
depended on how well they had done in relation to how well they thought they had done. Most students wanted feedback more when they had done worse than expected. This is contrary to the suggestion that Carless (2006) made that better students are more receptive to feedback because they have greater confidence and understanding of what good performance entails. For weaker students feedback risks having a negative emotional impact.

Dowden, Pittaway, Yost and McCarthy (2013) investigated the emotional connotations of feedback further. They showed that students expected written feedback to show them how to improve, which was especially important given the stress of being assessed. In particular the students in their study linked getting good feedback with having a good relationship with the teacher and the paper concluded that students should be taught how to respond to written feedback.

Other research shows that how a student feels about feedback can depend on who/what produces it. Lipnevich and Smith (2009) found that students reported they would rather receive feedback from a teacher than feedback that was computer-generated because the feedback would be personal and more trustworthy. Furthermore, where there were plenty of comments, students were pleased with the teacher's commitment to their learning. Students who did not receive detailed feedback reported being discouraged.

A number of papers have reported that students and staff have different perceptions about feedback. Orsmond and Merry (2011) found that almost all the students they interviewed thought feedback helped their learning (see also Perera, Lee, Win, Perera \& Wijesuriya, 2008). Their perception of feedback differed from tutors in that they evaluated feedback in terms of how it could help with future assignments rather than how it could help them develop into professionals. Orsmond and Merry (2011) recommend that tutors discuss their intentions in providing feedback with students. This is similar to Carless (2006)'s recommendation that there are assessment dialogues to reduce the misconceptions and differing perceptions of students and staff.

Blair and McGinty (2013) found that students valued the opportunity to discuss their feedback in a one-to-one setting with lecturers and that students reported that dialogue with a tutor they felt cared about them led to improvements in their work. Blair and McGinty describe students tenaciously chasing feedback dialogue opportunities, suggesting that the students placed high value on these.

However, Robinson, Pope, and Holyoak (2013) report that students were scared of approaching their tutors. While they found that both students and staff valued feedback, they also found that students expected it to offer all the answers for how to improve their work, whereas staff saw feedback as just a starting point for improvement efforts. They also suggested that student dissatisfaction with feedback stemmed from a lack of skills in making use of it and that apparent disinterest arose from not knowing what they should do with feedback.

While there seems to be consensus that students value feedback, this still leaves questions regarding the extent to which they value feedback, what they value it for and what conditions create an environment where feedback is more or less valued. The literature suggests that the value students place on feedback is different to that placed on it by tutors, so the value feedback has to students merits its own investigation. The literature also suggests that the students' emotional relationship to the feedback is likely to play a role in the students' judgement as to its worth. However, there are likely to be other conditions that affect these value judgements that have not yet been considered by the literature.

\section{Method}

This study involved descriptive, qualitative research using an inductive approach. There was no initial hypothesis. Student focus groups were held in six science departments and on a scientific cross-disciplinary degree in a UK research-intensive university. Overall, a total of 79 students took part. The majority of students were undergraduate, although some masters' students were represented. The students were all volunteers, with participation incentivised by book tokens. The focus groups explored a wide range of questions about the students' experience of and views about assessment and feedback. They were recorded and professionally transcribed. Responses were analysed by first identifying data relating to the importance and value of feedback to students, this data was then analysed for emergent themes. Of particular importance were responses to questions that explored the students' views on the feedback they have experienced and how these experiences have affected the students' engagement with their degree, whether the students would recommend their course, and the students' views of the institution. Students were also asked about their views as to the purpose of feedback, feedback opportunities they did not take up, and the use of feedback. The views reported on cannot be considered representative but they offer an insight into some of the factors that influence the value of feedback to some students and they show that contrary to the impression one gets from the literature not all students value feedback.

During the focus groups, the students were questioned on their understanding of the term 'feedback'. The students had a broad understanding of the concept, which included the grades they received, annotated scripts, written feedback, general written feedback to the class, oral feedback, face-to-face marking, online feedback from quizzes, model answers, 
tutorials, problem classes and workshops, meetings with tutors, feedback on questions in lectures and the students' on-going relationships with tutors. Feedback is thus understood in this paper to be any mechanism by which students can gain an understanding of their current ability and/or understanding in relation to their subject of study; this is often but not exclusively by means of gaining an understanding of their performance on a particular task. The feedback may not directly tell the students about their own ability; with model answers for example students need to compare their own answers to the model answers in order to determine what the comparison tells them about their current ability to solve such problems.

Nevertheless, it is clear that the students had different conceptions of feedback from each other. Where the students are clearly only talking about feedback on a piece of assessed work, rather than on other indications of their current ability/understanding such as feedback on questions in lectures or students' ongoing relationships with staff, I have used the term 'feedback on assessed work'. There are times when it is likely that the students use the term 'feedback' to mean a commentary on their assessed work, but this was not clear enough on any occasion to merit a distinction from feedback on assessed work.

\section{Results}

It is evident from the focus groups reported on in this paper, that the students varied in the value they placed on feedback. For some of the students, feedback had associations with learning, for others it was associated with motivation and/or pastoral care. For some students feedback was very important, for others less so. Some 'loved' their teachers despite poor quality feedback, for others it indicated a disorganised, uncaring organisation. Perhaps unsurprisingly, feedback was spoken of in the context of the UK fee regime, with the implication that feedback was part of a 'contract' between teachers and students.

\subsection{The Importance of Feedback for Learning}

Many of the students recognised the importance of feedback to their learning (though also see below for examples of where this was not the case). A number of students thought feedback on assessed work was important because they needed to know where they had gone wrong. Another said that feedback on assessed work was important because she revised from her coursework.

"That's [consistent, detailed feedback on assessed work is] really important, because we could spend hours doing it, but if you've got it wrong then..." (Male Earth Sciences student).

"I am quite bothered, because I want to use that [coursework] to revise towards the exam, so I think feedback is needed." (Female Chemistry student)

Others used feedback on assessed work to determine what made a good piece of work: "different lecturers mark things in different ways, have different styles, so it's interesting to break the course down a little bit and just see what they're looking for, exactly." (Female Earth Sciences student)

Students in various departments said that feedback motivated them: they worked more on modules that gave good feedback because they cared more about those modules. In contrast others said that they worried less about modules where they got more feedback, as they knew what was required of them and so did less work.

"it probably tends to make you do more work towards the modules that you get more feedback from, I guess. Or the stuff you're getting less back from, you're probably less likely to care as much about." (Male Earth Sciences student)

"I don't know, some part of me, like, if I'm not getting feedback, it makes me a bit more worried about how well I'm going to do, so I have to put more time into it, because I don't know what they want." (Female Earth Sciences student)

The issue of motivation also came up in a more oblique way. One student said that it was really important for him to know what he was capable of:

"the reason I got a 58 say was because my first two questions were strong, and then I got let down on my third. And if that's the case, I'd rather know that then say, "oh, you can only really hit in the high 50s, you're not good enough to get a mark in the high 60s or low 70s." (Male Science \& Technology Studies student)

This quote speaks to the mark-as-feedback providing students with self-efficacy. He saw the breakdown of the mark as providing him with feedback as to whether he could do better. However, this student's concept of self-efficacy was not fully developed. He spoke of the most important purpose of assessment as being to show him his strengths and he would select modules on the basis of those strengths. He associated interest with effort leading to a good mark, so logically this would suggest that he thought the selected modules would also reflect his interests. However, he also spoke of the importance of getting a good degree in the context of student fees:

"if I come out of university with a 2-2, there's no point in me going to university, in some senses, because you can't get 
on to a graduate scheme, you can't get into academia, obviously, you can't get on to a Masters programme. ... coming out of university with $£ 25,000$ worth of debt is a lot of money, to have said, 'okay, I’ve got a 2-2, what can I actually do with this'”' (Male Science \& Technology Studies student)

The idea that feedback was important, so students knew how they were doing, was shared across the faculty:

"I think I really need it, I really need to have good feedback and to have a mark, so, to compare where am I. Am I good? Am I bad? What should I do?" (Male Earth Sciences student)

\subsection{Students' Place in the University}

Some students saw the quality of feedback they received as a reflection of their importance: with poor quality feedback being seen as unfair and in a number of departments the students said that little or low quality feedback made them feel unsupported and faceless.

"I guess the fact that we're not - there's not much feedback in assessment, sort of adds to the whole feel of completely not personal and no pastoral care at all." (Male Natural Sciences student)

One student thought it was unfair that students got low quality feedback on assessed work, since they had put effort into the work - she therefore saw poor quality feedback on assessed work as a breach of a tacit agreement between teachers and students.

"And for the amount of time we spend on it, really, just to get a grade on it and no feedback at all, seems a bit unfair, we put so much effort in, and get no feedback." (Female Chemistry student)

Unsurprisingly, this tacit agreement was spoken of in the context of student fees - suggesting that these students' views were informed by a consumerist model of Higher Education:

"I'm paying extortionate fees, and I don't get the feedback, and it's kind of, you know, there are the universities where I wouldn't have to pay so much, and I don't get as much back" (Female Earth Sciences student)

When asked how their view of feedback affected their view of the university, a number of students responded that they felt let down and now had very negative views of the university and particularly of its organisation.

"Yeah, it [assessment and feedback] does [affect my views of the university] in a way, because that's how you find out how much the university cares about your Degree." (Female Mathematics student)

This view was not unanimous though. Other students said that the quality of feedback on assessed work did not affect their view of the university.

"I don't sort of hold a grudge against [the university], "God, their homework feedbacks has really ruined my Degree experience." It's just something that is an inconvenience." (Male Mathematics student)

\subsection{Low Value of Feedback}

Not all of the students in the focus groups valued feedback. One student was unconcerned with the quality of the feedback on assessed work she received because the coursework had little weighting and so she had put little effort into the work. However, she added that if the feedback on assessed work was of a higher quality she might be "bothered" about it.

In mathematics there was a virtual consensus amongst the students that feedback was not particularly important. The mathematics students said that though they were unhappy with the feedback they received, that did not affect their engagement with their degree - it was just an "inconvenience" because assessment was important but feedback was not.

"the main thing is the assessment, ... - although it would be nice to get some feedback, some appropriate feedback from the department, but the assessment is what I enjoy and what I believe is the most important part of our Degree." (Male Mathematics student)

Another student expressed views that staff thought feedback was unimportant and seemed unclear as to whether she agreed:

"Because with Maths, I think that they believe - and this is probably partly true, as well, that if you learn it, you can just like learn it and know it, and if you don't learn it, then, you know, you have a problem with not learning it, and there's only so much somebody else can tell until you learn this stuff. ... So, even if they were to give me feedback, like, "you should improve this, you should improve this," it's like I'll kind of know that myself anyway." (Female Mathematics student)

A few students explicitly compared feedback to other aspects of their learning experience. Some said that while feedback was important, class size was more important in whether they would recommend their degree. Others agreed on feedback's importance, but said that they would choose high quality teaching over high quality feedback. Others said 
that despite their negative views on the feedback they received they would still recommend their degrees.

"I think it's important, especially with feedback... But, I don't know. I think I would rather have an amazing standard of teaching and lesser quality assessment, personally." (Female Science \& Technology Studies student)

\section{Discussion}

As discussed in section 1.1 above, Brown (2007) found that students value feedback more when they do worse in their assessment task than expected. Many of the students in the focus groups also valued feedback on assessed work when they had not done well; a lot of the statements about feedback's importance to learning were around learning from mistakes (see 3.1 above). Students also spoke of seeking out feedback on assessed work when they were dissatisfied with their mark:

"you can take your exams and you get a grade, but you really don't know how that grade came about, and I wasn't satisfied with my marks that I got from it. So, I went to see my tutor and he let me see the exams." (Female Science \& Technology Studies student)

Feedback from exams was discussed in a number of the focus groups, with students saying that they would appreciate getting feedback on exam performance. This suggests that feedback's value is noticed where feedback on assessed work is absent.

The students valued feedback on assessed work where there was inadequate guidance on assignments, as it helped to clarify expectations for future pieces of work:

"they never tell you what they're expecting in that essay. So, you can find you can spend ages researching these things and then it's completely wrong, but you don't know, until you get some kind of feedback" (Female Natural Sciences student)

The fee regime in the UK has also created conditions in which the students value feedback on assessed work because it represents value for money and the provision of feedback on assessed work is part of the university's side of the agreement (see 3.2 above). However, these conditions do not help to create a sense of feedback as intrinsically valuable.

The students generally valued feedback on assessed work in conditions that aided feed-forward. One of the Chemistry students spoke of the value of feedback on assessed work when the coursework was linked to the exams: so she could use the feedback on assessed work for revision (see 3.1 above). Another Chemistry student spoke of the lack of value of feedback on assessed work had because the coursework was not worth much, so she had not tried hard in the coursework (see 3.3 above). By increasing the stakes of the assessment, the results of it are more likely to represent the students' capabilities at that point in time and thus increase the value of the feedback on assessed work to them. One of the mathematics students spoke of the lack of value of feedback because all it could tell her was what she already knew - that she did not know how to solve certain problems (see 3.3 above). Thus the students in the focus groups would have benefitted from conditions where they understood that feedback can help them to improve and where they knew how to use it for this purpose.

\section{Conclusion}

It is clear from the literature that scholars who publish on assessment and feedback, place great value on feedback. They make a strong case that staff and students should value feedback too. What they make a far weaker case for is that students do value feedback. Though a number of papers claim students value it, none have really studied this - students are bound to say they want feedback because it appears to cost them nothing. As one student said in one of the focus groups:

"bring in more feedback ... more feedback's welcome ... it's not going to harm us. Maybe it will harm the department with their time allocation (laughs) but ..." (Male Statistics student)

More than this, feedback acts as a symbol to some students - a sign of the student's value to their lecturers and the university and a sign that the university is fulfilling its side of the implicit 'contract' that has been created with the concept of students as consumers. This makes the concept of 'value' a complicated one in the context of feedback and it may be that a single term cannot capture the multitude of meanings that feedback can have for students.

When the symbolic aspects of feedback are stripped away, the extent that the students in the focus groups intrinsically valued feedback is far less clear. Furthermore, feedback does cost students. If staff are busy providing feedback, particularly on assessed work, they have less time for other educational practices. When the comparison was made - the students reported that they would rather have smaller class sizes or excellent teaching. Taken alongside the weak correlation between assessment and feedback satisfaction and overall satisfaction in the UK's National Student Survey and high levels of uncollected feedback across the sector, this suggests that students do not place much intrinsic value on feedback. Further research is required to test this hypothesis. 
The students in the focus groups valued feedback on assessed work in situations that aided feed-forward: where assignments clearly linked to each other and the exams; where assessments were worth enough of a module to make them worthy of a students' full effort; and where the feedback on assessed work made it clear how to improve future work. I believe that these students would also benefit from more education as to how valuable feedback can be and how to make best use of it. More research is required to see how generalisable this is to other students in different contexts. Only when students intrinsically value feedback enough to collect feedback on assessed work, take up opportunities for other feedback, and make best use of all the feedback they receive, will feedback be able to fulfil its potential for improving student performance.

\section{Acknowledgements}

This paper is based on a research project into assessment and feedback in a science faculty. I led the project and conducted the majority of the focus groups. Additional focus groups were run by Dr Jason Davies and Mrs Abbie King. The transcriptions were coded by Dr Andrew Chilvers and the project administered by Mr Andrew Bishop. Dr Nick Grindle and two anonymous referees offered extremely valuable thoughts and comments on a draft. Dr Teresa McConlogue organized writing days, where much of this paper was written and has been very supportive throughout. Thank you all for your contributions and to all the students who took part in the focus groups.

\section{References}

Black, P., \& Wiliam, D. (1998). Inside the Black Box: Raising Standards Through Classroom Assessment. Phi Delta Kappan, 80, 139-148. Retrieved from http://search.proquest.com/docview/218533069?accountid=14511

Blair, A., \& McGinty, S. (2013). Feedback-dialogues: exploring the student perspective. Assessment \& Evaluation in Higher Education, 38, 466-476. http://dx.doi.org/10.1080/02602938.2011.649244

Brown, J. (2007). Feedback: the student perspective. Research in Post-Compulsory Education, 12, 33-51. http://dx.doi.org/10.1080/13596740601155363

Buxley, A. (2012). National Student Survey: Analysis of national results for 2011. Retrieved from https://www.heacademy.ac.uk/sites/default/files/nss_report_2011_final.pdf

Carless, D. (2006). Differing perceptions in the feedback process. Studies in Higher Education, 31, 219-233. http://dx.doi.org/10.1080/03075070600572132

Dowden, T., Pittaway S., Yost, H., \& McCarthy, R. (2013). Students' perceptions of written feedback in teacher education: Ideally feedback is a continuing two-way communication that encourages progress. Assessment \& Evaluation in Higher Education, 38, 349-362. http://dx.doi.org/10.1080/02602938.2011.632676

Ferguson, P. (2011). Student perceptions of quality feedback in teacher education. Assessment \& Evaluation in Higher Education, 36, 51-62. http://dx.doi.org/10.1080/02602930903197883

Gibbs, G., \& Simpson, C. (2004). Conditions under which assessment supports students' learning. Learning and Teaching in Higher Education, 1, 3-31. http://www2.glos.ac.uk/offload/tli/lets/lathe/issue1/issue1.pdf

Hattie, J., \& Timperley, H. (2007). The power of feedback. Review of Educational Research, 77, 81-112. http://dx.doi.org/10.3102/003465430298487

Lipnevich, A. A., \& Smith, J. K. (2009). "I really need feedback to learn:" students' perspectives on the effectiveness of the differential feedback messages. Educational Assessment, Evaluation and Accountability, 21, 347-367. http://dx.doi.org/10.1007/s11092-009-9082-2

Orsmond, P., \& Merry, S. (2011). Feedback alignment: effective and ineffective links between tutors' and students' understanding of coursework feedback. Assessment \& Evaluation in Higher Education, 36, 125-136. http://dx.doi.org/10.1080/02602930903201651

Perera, J., Lee, N., Win, K., Perera, J., \& Wijesuriya, L. (2008). Formative feedback to students: the mismatch between faculty perceptions and student expectations. Medical Teacher, 30, 395-399. http://dx.doi.org/10.1080/01421590801949966

Rae, A. M., \& Cochrane, D. K. (2008). Listening to students: How to make written assessment feedback useful. Active Learning in Higher Education, 9, 217-230. http://dx.doi.org/10.1177/1469787408095847

Robinson, S., Pope, D., \& Holyoak, L. (2013). Can we meet their expectations? Experiences and perceptions of feedback in first year undergraduate students. Assessment \& Evaluation in Higher Education, 38, 260-272. http://dx.doi.org/10.1080/02602938.2011.629291

Sinclair, H. K., \& Cleland, J. A. (2007). Undergraduate medical students: who seeks formative feedback?. Medical 
Education, 41, 580-582. http://dx.doi.org/10.1111/j.1365-2923.2007.02768.x

Weaver, M. R. (2006). Do students value feedback? Student perceptions of tutors' written responses. Assessment \& Evaluation in Higher Education, 31, 379-394. http://dx.doi.org/ 10.1080/02602930500353061

This work is licensed under a Creative Commons Attribution 3.0 License. 